\title{
Decomposition of Socioeconomic Inequality in Catastrophic Health Expenditure: An Evidence from Iran
}

\author{
Sajad Vahedi ${ }^{\mathrm{a}}$, Aziz Rezapour ${ }^{\mathrm{b}, *}$, Farzad Faraji Khiavi ${ }^{\mathrm{a}}$, Firooz Esmaeilzadeh ${ }^{\mathrm{c}}$, \\ Javad Javan-Noughabi ${ }^{\mathrm{b}}$, Abdollah Almasiankia ${ }^{\mathrm{d}}$, Abbas Ghanbari ${ }^{\mathrm{b}}$ \\ ${ }^{a}$ Department of Health Services Managment, School of Health, Ahvaz Jundishapur University of Medical Sciences, Ahvaz, Iran \\ ${ }^{\mathrm{b}}$ Health Management and Economics Research Center, Iran University of Medical Sciences, Tehran, Iran \\ ${ }^{c}$ Department Public Health, School of Public Health, Maragheh University of Medical Sciences, Maragheh, Iran \\ ${ }^{\mathrm{d}}$ Burn and Wound Healing Research Center, Shiraz University of Medical Sciences, Shiraz, Iran
}

\section{A R T I C L E I N F O}

\section{Keywords:}

Health expenditures

Healthcare disparities

Socioeconomic factors

Inpatients

Iran

\begin{abstract}
A B S T R A C T
Background: Evidences showed that the incidence of catastrophic health expenditure is unequally distributed among disadvantaged populations. The present study has tried to explain the contributors of this unfair inequality in Hamadan, Iran.

Methods: The target population was households that utilized inpatient services in hospitals of Hamadan. A proportional stratified random sampling method was used to determine study sample $(\mathrm{N}=770)$. The associated factors of catastrophic health expenditure were estimated using logistic regression analysis. The inequality of catastrophic health expenditure was measured by concentration index and explained by decomposition analysis. The data were analyzed by using STATA version 12 .

Results: The key determinants of catastrophic health expenditure were poor economic status, lower household size, lack of supplementary insurance and the number of hospitalizations. The overall concentration index of catastrophic health expenditure in Hamadan was -0.163 (95\% CI: -0.242 to -0.083 ). Household economic status $(63.60 \%)$ and household size $(39.90 \%)$ were considered as the first and the second largest contributors of catastrophic health expenditure inequality, respectively.

Conclusion: It is demonstrated that catastrophic health expenditure inequality in Iran could be explained by the factors beyond the health sector scope. Hence, future policy efforts need to consider both health system factors and the factors beyond the health system to eliminate catastrophic health spending burden and its inequality.
\end{abstract}

\section{Introduction}

Protecting households from illness-related financial catastrophe alongside increasing health outcomes are increasingly playing more fundamental roles in healthcare system. ${ }^{1,2}$ Out-of-pocket (OOP) health expenditure that goes far from certain proportions of a household's financial capacity has been accounted as catastrophic health expenditure. ${ }^{3,4}$ Catastrophic health Expenditure (CHE) could severely affect households living conditions and in its higher degree pushing them into poverty. ${ }^{5}$ It is reported that 150 million people worldwide suffer from financial catastrophe each year and 100 million are impoverished because of direct payments for health services. ${ }^{6,7}$

Although it is emphasized that a desirable health system need to ensure that its stakeholders have effective access to required care without suffering from financial hardship ${ }^{1,8}$ evidences showed that the incidence of CHE is unequally distributed among disadvantaged populations. ${ }^{2,9}$ Despite the fact that "average" catastrophic health spending could be reduced by policy interventions, inequalities in CHE will not simply be eliminated and inevitably exist across households due to the diverse socioeconomic factors. ${ }^{10}$ Hence it is important to measure the inequalities in facing CHE and quantify the determinants of its inequality. ${ }^{9}$

The adverse organization of healthcare financing, ${ }^{8,11,12}$ along with diverse socioeconomic factors, could increase the risk of catastrophic health payment. The health system of Iran suffered from high degrees of CHE. The adverse status of these payments has been highlighted in

\footnotetext{
* Corresponding author.

E-mail addresses: vahedi.s3@gmail.com (S. Vahedi), rezapour.a@iums.ac.ir (A. Rezapour), farajifarzad@yahoo.com (F.F. Khiavi), firooz.esmaeilzadeh@gmail.com (F. Esmaeilzadeh), javadjavan.n@gmail.com (J. Javan-Noughabi), almasiana@yahoo.com (A. Almasiankia), salar7408@gmail.com (A. Ghanbari).
} 
different studies, in national ${ }^{13-15}$ and subnational level. ${ }^{16,17}$ Moreover, previous research revealed that this adverse outcome had been unevenly distributed among poor Iranian households. ${ }^{9,11}$ In present study, we investigated the inequality of CHE for households that have used inpatient healthcare services in Hamadan, a less investigated province with regard to catastrophic payments, and analyze the determinants of this inequality to bring some policy implication.

\section{Materials and methods}

\subsection{Study setting}

The required data of this cross-sectional study was obtained from former survey that carried out in 2014 in Hamadan city. The target population in this survey consisted of the households that have member with inpatient services utilization in 8 hospitals of Hamadan. Proportional stratified random sampling method was used for sampling. it was performed in three steps. Frist, the total number of hospitalized patients in 6 months of 2014 (21 March to 22 September) were found. In the second step, the sampling weight was calculated according to the proportion of hospitalized patients for each hospital. Finally, the sample size for each hospital was obtained by multiplying the sampling weight to the total sample size. The total sample size of the present study was calculated using the Cochran formula in which $\mathrm{p}=12 \%$ (Proportion of the households face with CHE), ${ }^{9} \mathrm{~d}=0.0228$, and $\alpha=0.05$ (Type I error). Accordingly, a sample size of 780 households was determined for this study. After data cleaning (i.e. excluding the households with variables missing), the analysis was performed for 770 households. The household-related section of the World Health Survey questionnaire was used in this survey to measure OOP and demographic and socioeconomic factors. The validity and reliability of this questionnaire were verified in previous research. ${ }^{9}$

\subsection{Catastrophic health expenditure and its determinants}

The capacity to pay (CTP) approach ${ }^{18}$ was followed to measure CHE. According to this approach, CTP was obtained from difference between effective income (measured by total expenditure) and basic subsistence needs. Health care expenditure would be considered 'catastrophic' if it was equal to or higher than $40 \%$ of the household's CTP. Based on this approach, a binary variable could be defined to capture catastrophic payment. The logistic regression analysis was used to investigate the impact of the determining variables (supplementary insurance status, sex of household head, household size, having a member over 60 years, having a member below 6 years, having a disabled member, economic status and reporting inpatient service usage)on the CHE.

\subsection{Catastrophic health expenditure inequality and its determinants}

We used concentration index (CI), one of the most widely accepted techniques to identify health inequalities, ${ }^{19,20}$ to measure the socioeconomic inequality in CHE. To investigate the determinants of CHE inequality, regression-based decomposition was applied. ${ }^{21,22}$ The details of this method are explained in previous researches. ${ }^{2,10}$ The data were analyzed by using STATA 12 (STATA Corporation, College Station, TX). P values less than .05 were considered statistically significant.

\section{Results}

Table 1 shows the summary statistics for independent variables. Eighty six (11.2\%) households had female household heads. The Mean household size was 4.11 (SE $=.17$ ), and $69.2 \%$ of the households had 36 members. A Majority of households reported no supplementary insurance coverage. The incidence of disabled member was $10.6 \%$. Our result revealed that in Hamadan, 160 households (20.8\%; 95\% confidence interval (CI): 17.9-26\%) experienced CHE.

\subsection{Determinants of catastrophic health care expenditure}

Table 2shows the logistic regression results of determinant factors of CHE in Hamadan. Except for the second quintile, we observe no significant association between economic status and incurring CHE; this means that the households belonging to this economic quintile have higher probability to pay remarkable proportion of their earnings to use required health care services.

As seen in Table 3, the increase in hospitalization would pose the households in financial hardship. The Absence of supplementary insurance is another significant factor that could increase experiencing CHE; in this regard, households that did not have any type of supplementary health insurance were more likely to confront with financial hardship than those that had advantage of these insurance programs. Besides, the lower household size significantly increased the chance of CHE in comparison to larger ones'. Although it was seen that having disabled member and having member $\geq 60$ positively related to $\mathrm{CHE}$, this was not significant in this study. Meanwhile, female household heads and having children below 5 years insignificantly decreased the chance of incurring CHE.

\subsection{Socioeconomic inequality in catastrophic health care expenditure}

Fig. 1 shows the concentration curves for catastrophic payment in Hamadan. It was laid above the line of equality, this indicates that the CHE was more concentrated among the disadvantaged households. Testing the concentration curve dominance showed that the concentration curve of CHE significantly located above the line of equality. Moreover, related concentration index for CHE was - 0.163 (95\% CI: -0.242 to -0.083 ). The negative value of this index indicates that poor households had higher probabilities of facing CHE.

\subsection{Decomposition of inequality in catastrophic health care expenditure}

Table 3 shows the decomposition results for the concentration index of the Ln odds of catastrophic payments in Hamadan. This table represents the concentration index and relative contributions of each determinant of inequality in CHE. Here; the negative value of the concentration index demonstrates that the "interest" variable unevenly concentrated amongst the poor and vice versa. In this regards, variables such as having household members over 65years, having disabled member and female household heads had been distributed in low income households.

The grouped contribution per category variable is shown in last column of Table 3. The Positive value of variable's contribution indicates that relevant variables increase inequality, and vice versa. The findings revealed that the majority (near 64\%) of CHE inequalities could be explained by households' economic status. Besides, the household size (about40\%) is the second contributor of CHE inequality in Hamadan. moreover, having members aged over 65 years, disabled members, and members younger than 5 years old would increase the inequality. The Number of hospitalization (about -14\%), female household heads $(3.28 \%)$ and the lack of supplementary insurance $(-1.15 \%)$ negatively contributed to the studied socio-economic inequality.

\section{Discussion}

Present study showed that for more than one fifth of households that used inpatient services, health expenditure levels was more than $40 \%$ of their nonfood expenditures. This is higher than the overall CHE incidence assessed by another Iranian study that investigated the determinants of CHE among households that had hospitalized members. ${ }^{23}$ While this result is inconsistent with most previous studies that 
Table 1

Socioeconomic characteristics of the study population.

\begin{tabular}{|c|c|c|c|c|}
\hline \multicolumn{2}{|l|}{ Variable } & \multirow{2}{*}{$\begin{array}{l}\text { Description } \\
1 \text { if the } 20 \% \text { low income households, } 0 \text { otherwise }\end{array}$} & \multirow{2}{*}{$\begin{array}{l}\mathrm{N}(\%) \\
155(20.1)\end{array}$} & \multirow{2}{*}{$\begin{array}{l}\text { Mean (S.D.) } \\
-\end{array}$} \\
\hline Economic status & Quintile 1 (poorest) & & & \\
\hline & Quintile 2 (Poor) & 1 if the $20 \%$ low middle income households, 0 otherwise & $152(19.7)$ & - \\
\hline & Quintile 3 (Middle) & 1 if the $20 \%$ middle income households, 0 otherwise & $155(20.1)$ & - \\
\hline & Quintile 4 (Rich) & 1 if the $20 \%$ high middle income households, 0 otherwise & $154(20.0)$ & - \\
\hline & Quintile 5 (Richest) & 1 if the $20 \%$ high income households, 0 otherwise & $154(20.0)$ & - \\
\hline \multirow[t]{2}{*}{ Disabled member } & Have & 1 if having household members suffer from disability, 0 otherwise & $80(10.6)$ & - \\
\hline & Not have & 1 if no household members suffer from disability, 0 otherwise & $690(89.4)$ & - \\
\hline \multirow[t]{2}{*}{ Household head } & Male & 1 if the head of household was male, 0 otherwise & $684(88.8)$ & - \\
\hline & Female & 1 if the head of household was female, 0 otherwise & $86(11.2)$ & - \\
\hline \multirow[t]{3}{*}{ Household size } & 1-2 members & 1 if household members is $1-2,0$ otherwise & $177(23.0)$ & - \\
\hline & 3-6 members & 1 if household members is $3-6,0$ otherwise & $533(69.2)$ & - \\
\hline & $\geq 7$ members & 1 if household members is $\geq 7,0$ otherwise & $60(7.8)$ & - \\
\hline \multirow[t]{2}{*}{ Member $\geq 65$} & Have & 1 if household having members over 65 years old, 0 otherwise & 347 (45.9) & - \\
\hline & Note have & 1 if all household members below 65 years old, 0 otherwise & $423(54.1)$ & - \\
\hline \multirow[t]{2}{*}{ Member $\leq 5$} & Have & 1 if household having members below 5 years old, 0 otherwise & $184(23.9)$ & - \\
\hline & Note have & 1 if all household members over 5 years old, 0 otherwise & $586(76.1)$ & - \\
\hline Supplementary & Have & 1 if all household members covered by supplementary health insurance, 0 otherwise & 184 (23.9) & - \\
\hline Insurance status & Note have & 1 if all household members not covered by supplementary health insurance, 0 otherwise & $586(76.1)$ & - \\
\hline \multicolumn{2}{|c|}{ Number of hospitalization } & Total number of hospitalization for each of household members & & $2.024(2.525)$ \\
\hline
\end{tabular}

reported CHE incidence in national ${ }^{11,13-15,24}$ and subnational ${ }^{9,16}$ contexts, as former research in Kermanshah ${ }^{25}$ as well as Ferdows ${ }^{26}$ reported high degrees of CHE incidence. In the mentioned studies, inpatient service use is one of the major determinants of facing with catastrophic payments. Generally, Inpatient healthcare services consist of very expensive healthcare services. Lack of financial protection can increase vulnerability of households versus CHE. ${ }^{24}$ This study also well highlighted that hospitalization costs can increase the incidence of CHE. National and sub-national authorities must listen to ear-splitting alarm of CHE incidence and pay attention to this adverse outcome, especially for households with remarkable inpatient expenditures, which may push the households into poverty.

Although other studies in $\operatorname{Iran}^{9,15,16,27}$ and other countries ${ }^{2,28}$ proved that lower economic status has a remarkable role in incurring CHE, while we only found a significant relationship between CHE and second economic quintile. This means that poorest households, due to inpatient services, may decrease their health care needs. This result is in line with a previous study conducted in China. ${ }^{10}$ Former research that conducted in some Asian countries also revealed that wealthier households, compared with disadvantaged ones, devoted a larger proportion of their earnings to healthcare services. This may confirm that the poor households avoid the utilization of healthcare services. ${ }^{29}$ This is a drastic problem for the health sector that its clients neglect their health care needs. Hence, required policies must be designed and implemented not only for reduction of catastrophic payments, but also for transformation of slept health-care needs to effective demands.

The findings revealed that lower household size significantly accompanied with higher probability of incurring catastrophic payments.
It is clear that households with lower breadwinners have lower capacity to pay and hence, devote large proportion of their incomes to utilization of health-care services. Previous research in $\operatorname{Iran}^{11,15}$ and other nations ${ }^{2,10}$ also reported the same result. Policy makers must be aware of this issue, and not only improvise an in-depth health insurance program for these households, but also improve business atmosphere for households with lower household size to earn much income. However, other studies ${ }^{14,30}$ reported that larger household size would increase the probability of facing with CHE.

Consistent with former researches in $\operatorname{Iran}^{11,16}$ and other countries, ${ }^{10,31}$ our findings demonstrated that the absence of supplementary insurance had raised the risk of CHE in Hamadan. Considering that most of the studied households had been covered by basic health insurance, this finding implicitly highlights the insufficiency of basic insurance plans to protect households from financial hardship in Iran. The failure of a previous intervention, ${ }^{9}$ which was designed to increase the effectiveness of health insurance programs in Iran, motivates the policy makers to broaden the coverage of these insurance plans in the framework of recent Iranian healthcare reforms.

Present study showed that CHE was unevenly distributed among disadvantaged households. Former national ${ }^{11}$ and regional ${ }^{9,12,23}$ studies also confirmed this result. Trying to explain the socioeconomic inequality in catastrophic payments through decomposition analysis we showed that most of this unfair inequality could be explained by household economic status. This finding is in line with a similar research in Tehran, which reported that more than $80 \%$ of CHE inequalities might be justified by economic status of the studied households. ${ }^{9}$ Former research ${ }^{22,32}$ that used decomposition analysis to

Table 2

The relationship between CHE and its determinants.

\begin{tabular}{|c|c|c|c|c|c|}
\hline \multicolumn{2}{|l|}{ Variable } & \multirow{2}{*}{$\frac{\beta . c o e f f i c i e n t}{0.5088875}$} & \multirow{2}{*}{$\frac{\text { P.value }}{0.126}$} & \multicolumn{2}{|c|}{$95 \%$ confidence interval } \\
\hline \multirow[t]{4}{*}{ Economic status } & Quintile 1 (poorest) & & & -0.1423959 & 1.160171 \\
\hline & Quintile 2 (Poor) & 0.7483503 & 0.019 & 0.1230486 & 1.373652 \\
\hline & Quintile 3 (Middle) & -0.1365969 & 0.699 & -0.8290423 & 0.5558485 \\
\hline & Quintile 4 (Rich) & 0.0792185 & 0.818 & -0.5943145 & 0.7527514 \\
\hline \multicolumn{2}{|c|}{ Having member disabled } & 0.3995435 & 0.176 & -0.179234 & 0.9783211 \\
\hline \multicolumn{2}{|c|}{ Female household head } & -0.1302501 & 0.646 & -0.6855178 & 0.4250176 \\
\hline \multirow[t]{2}{*}{ Household size } & $1-2$ members & 1.097957 & 0.023 & 0.1539057 & 2.042007 \\
\hline & 3-6 members & 0.340528 & 0.437 & -0.5183425 & 1.199399 \\
\hline \multicolumn{2}{|c|}{ Having member $\geq 60$} & 0.3111722 & 0.115 & -0.0761405 & 0.6984849 \\
\hline \multicolumn{2}{|c|}{ Having member $\leq 6$} & -.2712569 & 0.319 & -0.8052417 & 0.2627279 \\
\hline \multicolumn{2}{|c|}{ Lack of supplementary insurance } & .4682577 & 0.037 & 0.0289054 & 0.90761 \\
\hline \multicolumn{2}{|c|}{ Number of hospitalization } & .1852697 & 0.000 & 0.0981201 & 0.2724192 \\
\hline
\end{tabular}


Table 3

Decomposition analysis of concentration index of CHE in Hamadan (2014).

\begin{tabular}{|c|c|c|c|c|c|c|c|}
\hline \multicolumn{2}{|l|}{ Variable } & \multirow{2}{*}{$\begin{array}{l}\text { Coefficient } \\
0.4042196\end{array}$} & \multirow{2}{*}{$\begin{array}{l}\text { Mean } \\
0.2012987\end{array}$} & \multirow{2}{*}{$\begin{array}{l}\text { Elasticity } \\
-0.05183185\end{array}$} & \multirow{2}{*}{$\begin{array}{l}\text { Concentration index (CI) } \\
-0.79766806\end{array}$} & \multirow{2}{*}{$\begin{array}{l}\text { Contribution to CI } \\
0.04134461\end{array}$} & \multirow{2}{*}{$\begin{array}{l}\text { Contribution to CI \% } \\
63.60\end{array}$} \\
\hline Economic status & Quintile 1 (poorest) & & & & & & \\
\hline & Quintile 2 (Poor) & 0.5972205 & 0.1974026 & -0.07509759 & -0.39948254 & 0.03000018 & \\
\hline & Quintile 3 (Middle) & -0.1157077 & 0.2012987 & 0.01483685 & -0.00129702 & -0.00001924 & \\
\hline & Quintile 4 (Rich) & 0.0297246 & 0.2 & -0.0037869 & 0.39948254 & -0.0015128 & \\
\hline \multicolumn{2}{|c|}{ Having member disabled } & 0.3730934 & 0.1038961 & -0.02469194 & -0.10781489 & 0.00266216 & 2.43 \\
\hline \multicolumn{2}{|c|}{ Female household head } & -0.1576254 & 0.1116883 & 0.01121431 & -0.32075636 & -.00359706 & -3.28 \\
\hline \multirow[t]{2}{*}{ Household size } & 1-2 members & -0.7238929 & 0.6922078 & 0.31918994 & -0.352929 & 0.05167328 & 39.90 \\
\hline & 3-6 members & -1.082268 & 0.0779221 & -0.1118495 & 0.07253342 & -0.00811283 & \\
\hline \multicolumn{2}{|c|}{ Having member $\geq 60$} & 0.2607917 & 0.4506494 & -0.14641269 & -0.15762732 & 0.01180056 & 10.07 \\
\hline \multicolumn{2}{|c|}{ Having member $\leq 6$} & -0.1896802 & 0.238961 & 0.02887271 & 0.0674733 & .0674733 & 0.194 \\
\hline \multicolumn{2}{|c|}{ Lack of supplementary insurance } & 0.3692687 & 0.761039 & -0.17901435 & 0.00706943 & -0.00126553 & -1.154 \\
\hline \multicolumn{2}{|c|}{ Number of hospitalization } & 0.1478138 & 0.2701299 & -0.19063775 & 0.07895523 & -0.01505185 & -13.73 \\
\hline \multicolumn{2}{|c|}{ Ln of odds } & & - 1.569862 & & 0.10828493 & & \\
\hline \multicolumn{2}{|l|}{ Residual } & & & & & & 1.96 \\
\hline
\end{tabular}

quantify contributors of other health inequalities also reported that economic status plays an important role in the inequality between advantaged and disadvantaged Iranian households. Other studies in China, ${ }^{2,10}$ accounted the household size as the largest contributor of CHE inequality.

In this study, household size was demonstrated as the second largest (about 40\%) contributor of inequality in facing with CHE. This seems logical; as mentioned above, lower household size, that is concentrated among poor households ( $C I=-0.352929$ ), could increase the chance of incurring CHE. Compared with former research in Tehran, ${ }^{9}$ it is demonstrated that in Hamadan household size has larger contribution on CHE inequality. After these dominant contributors, having disabled persons and the members above 60years old has some positive contribution on CHE inequality in Hamadan.

Like other studies ${ }^{2,9,10}$ we found negative contribution of health service usages, measured by hospitalization, and CHE inequality. Since higher utilization of health service is concentrated among rich households; if the chance of CHE increases among them, the inequality in the number of households facing catastrophic costs in different socio-economic groups can be reduced. Contrary to expectations, the lack of supplementary insurance negatively contributed to CHE inequality. One possible explanation is that supplementary health insurance has not yet spread among wealthier families.

Considering that most of CHE inequalities are explained by factors beyond the health sector, it will be great if policy makers, alongside health financing reforms, try to eliminate socio-economic inequalities among households by distributional policies. However, bad implementation of these policies could leave some side effects on socioeconomic factors in the society. ${ }^{22}$ For example, the well-known substantial distributional policy in Iran, known as Targeted Subsidies, couldn't reach to its desired ideals. It is believed that this policy has some negative effects on health outcomes especially among poor people $^{33}$ and probably made them sensitive to CHE.

We have some limitation in our research which must be acknowledged. Decomposition analysis could not show causal relationship between CHE inequality and studied variables; hence the results of this study must be interpreted with caution. Like other studies, relinquishing healthcare needs because of their costs, increase in the capacity to pay by loaning, selling assets and decreasing in other expenditure is not reflected in our research. Hence, CHE incidence may be underestimated in this study.

\section{Conclusion}

The findings showed sever CHE incidence and inequality in Hamadan. Logistic regression showed that the lower socioeconomic status, lower household size, absence of supplementary insurance and increase in hospitalization will increase catastrophic health spending in Hamadan. Besides, decomposition analysis revealed that most of CHE inequalities could be explained by the factors such as economic status and household size that are beyond the health system scope. It is evident that an emphasis on health system intervention couldn't effectively dispel CHE inequality in communities; therefore, it is profoundly suggested that future policy efforts would simultaneously include health system factors and the factors beyond health system to eliminate CHE burden and its inequality, more effectively.

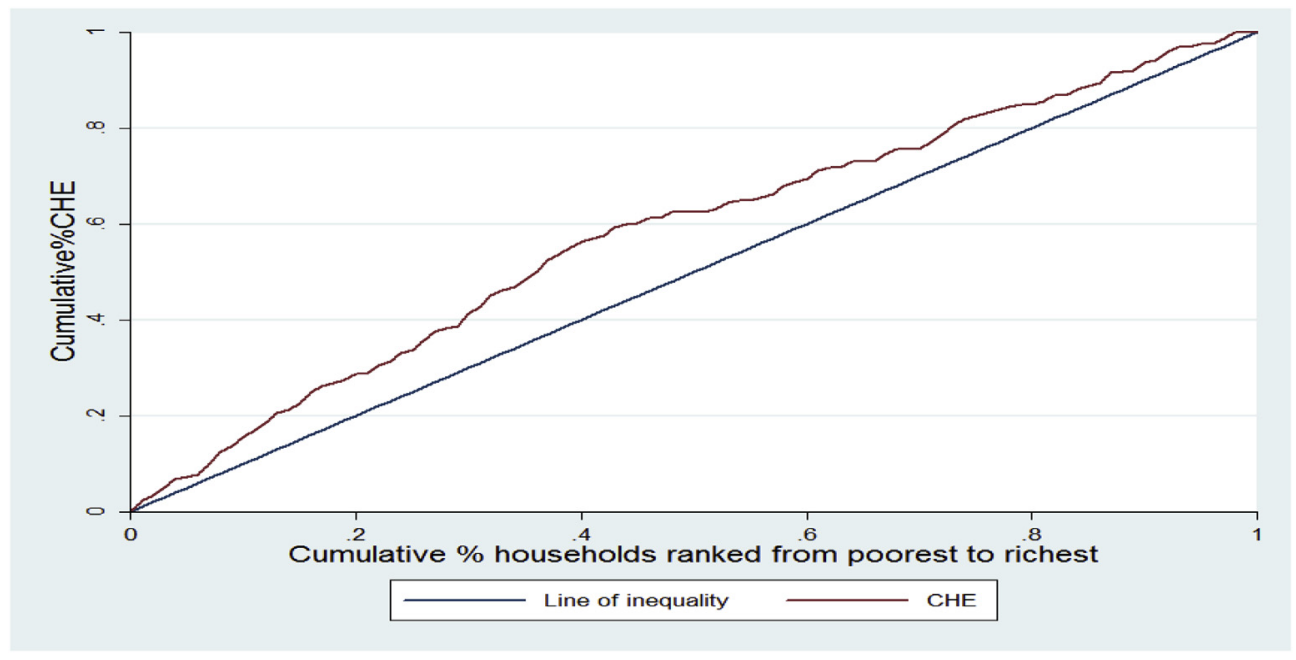

Fig. 1. Concentration curve of incurring CHE. 


\section{Funding}

This research received no funding support.

\section{Declaration of competing interest}

None.

\section{Acknowledgements}

The authors would like to appreciate generous and patient co-operation of study's participants.

\section{References}

1. World Health Organization. The World Health Report 2000: Health Systems: Improving Performance. World Health Organization; 2000.

2. Wang Z, Li X, Chen M. Catastrophic health expenditures and its inequality in elderly households with chronic disease patients in China. Int J Equity Health. 2015;14:8.

3. Li Y, Wu Q, Xu L, et al. Factors affecting catastrophic health expenditure and impoverishment from medical expenses in China: policy implications of universal health insurance. Bull World Health Organ. 2012;90:664-671.

4. Abolhallaje M, Hasani S, Bastani P, Ramezanian M, Kazemian M. Determinants of catastrophic health expenditure in Iran. Iran J Public Health. 2013;42:155-160.

5. Rezapour A, Vahedi S, Khiavi FF, Esmaeilzadeh F, Javan-Noughabi J, Rajabi A. Catastrophic health expenditure of chronic diseases: evidence from hamadan, Iran Int J Prev Med. 2017;8:99.

6. Kruk ME, Goldmann E, Galea S. Borrowing and selling to pay for health care in lowand middle-income countries. Health Aff (Millwood). 2009;28:1056-1066.

7. Xu K, Evans DB, Carrin G, Aguilar-Rivera AM, Musgrove P, Evans T. Protecting households from catastrophic health spending. Health Aff (Millwood). 2007;26:972-983.

8. Rezapour A, Ebadifard Azar F, Azami Aghdash S, Tanoomand A, Ahmadzadeh N, Sarabi Asiabar A. Inequity in household's capacity to pay and health payments in Tehran-Iran-2013. Med J Islam Repub Iran. 2015;29:245.

9. Kavosi Z, Rashidian A, Pourreza A, et al. Inequality in household catastrophic health care expenditure in a low-income society of Iran. Health Policy Plan. 2012;27:613-623.

10. Xu Y, Gao J, Zhou Z, et al. Measurement and explanation of socioeconomic inequality in catastrophic health care expenditure: evidence from the rural areas of Shaanxi Province. BMC Health Serv Res. 2015;15:256.

11. Hajizadeh M, Nghiem HS. Out-of-pocket expenditures for hospital care in Iran: who is at risk of incurring catastrophic payments? Int $J$ Health Care Financ Econ. 2011;11:267-285.

12. Rezapour A, Ebadifard Azar F, Azami Aghdash S, et al. Measuring equity in household's health care payments (Tehran-Iran 2013): technical points for health policy decision makers. Med J Islam Repub Iran. 2015;29:246.

13. Ghiasvand H, Abolghasem Gorji H, Maleki M, Hadian M. Catastrophic health expenditure among Iranian rural and urban households. Iran Red Crescent Med J. 2015;17:e30974 2013 - 2014
14. Fazaeli AA, Ghaderi H, Abbas Fazaeli A, Lotfi F, Salehi M, Mehrara M. Main determinants of catastrophic health expenditures: a Bayesian logit approach on Iranian household survey data (2010). Glob J Health Sci. 2015;7:335-340.

15. Moghadam MN, Banshi M, Javar MA, Amiresmaili M, Ganjavi S. Iranian household financial protection against catastrophic health care expenditures. Iran J Public Health. 2012;41:62-70

16. Kavosi Z, Keshtkaran A, Hayati R, Ravangard R, Khammarnia M. Household financial contribution to the health System in Shiraz, Iran in 2012. Int $J$ Health Policy Manag. 2014:3:243-249.

17. Karami M, Najafi F, Karami Matin B. Catastrophic health expenditures in kermanshah, west of Iran: magnitude and distribution. J Res Health Sci. 2009;9:36-40.

18. Xu K, Evans DB, Kawabata K, Zeramdini R, Klavus J, Murray CJ. Household catastrophic health expenditure: a multicountry analysis. Lancet. 2003;362:111-117.

19. Wagstaff A, Paci P, van Doorslaer E. On the measurement of inequalities in health. Soc Sci Med. 1991;33:545-557.

20. Vahedi S, Rezapour A, Mohammadbeigi A, Khosravi A. Economic inequality in outpatient healthcare utilization: the case of Iran. J Res Health Sci. 2018;18:e00424.

21. Wagstaff A, van Doorslaer E, Watanabe N. On decomposing the causes of health sector inequalities with an application to malnutrition inequalities in Vietnam. $J$ Econom. 2003;112:207-223.

22. Ramezani Doroh V, Vahedi S, Arefnezhad M, Kavosi Z, Mohammadbeigi A. Decomposition of health inequality determinants in shiraz, south-west Iran. $J$ Res Health Sci. 2015;15:152-158.

23. Ghiasvand H, Sha'baninejad H, Arab M, Rashidian A. Hospitalization and catastrophic medical payment: evidence from hospitals located in Tehran. Arch Iran Med. 2014; 17:507-513.

24. Yazdi-Feyzabadi V, Bahrampour M, Rashidian A, Haghdoost AA, Akbari Javar M, Mehrolhassani MH. Prevalence and intensity of catastrophic health care expenditures in Iran from 2008 to 2015: a study on Iranian household income and expenditure survey. Int $J$ Equity Health. 2018;17:44.

25. Daneshkohan A, Karami M, Najafi F, Matin BK. Household catastrophic health expenditure. Iran J Public Health. 2011;40:94-99.

26. Ghoddoosinejad J, Jannati A, Gholipour K, Baghban Baghestan E. Households en countering with catastrophic health expenditures in Ferdows, Iran. J Egypt Public Health Assoc. 2014;89:81-84.

27. Anbari Z, Mohammadbeigi A, Mohammadsalehi N, Ebrazeh A. Health expenditure and catastrophic costs for inpatient- and out-patient care in Iran. Int J Prev Med 2014:5:1023-1028.

28. Su TT, Kouyate B, Flessa S. Catastrophic household expenditure for health care in a low-income society: a study from Nouna District, Burkina Faso. Bull World Health Organ. 2006;84:21-27.

29. O'Donnell O, van Doorslaer E, Rannan-Eliya RP, et al. Who pays for health care in Asia? J Health Econ. 2008;27:460-475.

30. Brinda EM, Andres AR, Enemark U. Correlates of out-of-pocket and catastrophi health expenditures in Tanzania: results from a national household survey. BMC Int Health Hum Right. 2014;14:5.

31. Goldman DP, Zissimopoulos JM. High out-of-pocket health care spending by the elderly. Health Aff (Millwood). 2003;22:194-202.

32. Hosseinpoor AR, Van Doorslaer E, Speybroeck N, et al. Decomposing socioeconomic inequality in infant mortality in Iran. Int J Epidemiol. 2006;35:1211-1219.

33. Doshmangir L, Doshmangir P, Abolhassani N, Moshiri E, Jafari M. Effects of targeted Subsidies policy on health behavior in Iranian households: a qualitative study. Iran J Public Health. 2015;44:570-579. 